\title{
OSNOVNI ETIČNI POJMI - POSKUS PREGLEDA SODOBNEGA (NE)ETIČNEGA RAVNANJA
}

Povzetek Članek obravnava zapleteno problematiko, ki se nanaša na področje družbe, morale, etike, prava in vrednotnega sistema in je kot taka nadvse pomembna v življenju vseh posameznikov v družbi, neodvisno od tega, v katerem okolju ti delujejo. Članek med drugim podaja celovit pregled med vsemi do zdaj zapisanimi pravili, bodisi gre za prva sprejeta obča oziroma družbena pravila bodisi moralna, etična ali pravna pravila, pri čemer sta ob bok navedenemu postavljena še pomen in vloga vrednotne podstati.

Članek povzema bistvene opredelitve teoretičnih znanstvenih spoznanj, ki temeljijo na dejstvu, da so pojmi oziroma gradniki družbe, kot so morala, etika, pravo in vrednote, vrline oziroma kreposti posameznikov med seboj še kako zelo povezani in soodvisni, kakor tudi, da v času, v katerem živimo, predstavljajo nujni pogoj za dobro, dostojno in uravnoteženo življenje subjektov, če ne že kar rešitev za izhod iz krize.

Na podlagi izbranih metod, navedenih v nadaljevanju članka, so bili med drugim ugotovljeni tudi vzroki oziroma razlogi za krizo, v kateri smo danes. Ugotovljeno je bilo, da sta ravno odsotnost oziroma daljši proces (zaveden in nezaveden) odstiranja morale in etike s področij našega dosedanjega mišljenja, vedenja in delovanja ter neupoštevanje vrednot (vrednotna kriza) vzrok oziroma razlog za gospodarsko in socialno krizo, v kateri smo v resnici že dlje časa.

Ključne besede

Abstract The article discusses complex issues relating to the sphere of society, morality, ethics, law and value system, and is as such very important in the lifes of all individuals involved, regardless of the environment in which they operate. Inter alia, the paper 
provides a comprehensive review of all rules written so far, be it the first adopted general or social rules, or moral, ethical or legal rules, along with the importance and role of value foundation.

This article summarizes the main definitions of theoretic and scientific findings. These are based on the fact that terms or elements of society, such as morality, ethics, law and values or virtues of individuals are strongly connected and interdependent, and on the fact that, in the time we live in, they represent a prerequisite for a good, decent and balanced living, if not a solution to the crisis, which we are dealing with.

The methods, described in the article, served to identify the causes and reasons for the crisis, which we are facing today. It has been found that the disregard of values (value crisis) and the absence of or a long-term process (conscious and unconscious) of withdrawing morality and ethics from the areas of our thinking, behavior and actions so far, constituted the main reasons and causes for the economic and social crisis which has really been present for a while.

Keywords Society, law, morality, ethics, values.

Uvod O morali, etiki, pravu in vrednotah je veliko zapisano, zato se namen tega prispevka ne nanaša toliko na koncept splošne teoretizacije navedenih pojmov kot na koncept njihove ponovne osmislitve. Gre za paradigmo uporabnosti do zdaj spoznanega kot odgovor na vrednotno krizo oziroma za koncept splošne konkretizacije posameznikov v praksi. Opredelitve in teoretična spoznanja teh splošnih pojmov segajo že stoletja nazaj, so že dolgo zapisana in znana, pa vendar zato nič manj pomembna, zlasti v sodobnem času.

Namen navedenega $\mathrm{v}$ tem prispevku je tako $\mathrm{v}$ ponovni osvetlitvi pojmov, kot so družba, morala, pravo, etika in vrednotni sistem, v njihovi vlogi, pomenu in razsežnosti njihovega učinkovanja ter kritični primerjavi dosedanjih spoznanj različnih priznanih avtorjev o obravnavanih teoretičnih pojmih in njihovi uporabnosti $\mathrm{v}$ praksi - tudi v Slovenski vojski.

Bistvo tega članka se kaže v prispevku h krepitvi oziroma dvigu kritične zavesti posameznika o tem, kaj je pravno, moralno, etično in vredno (obenem). Gre za splošni kritični premislek oziroma vprašanje avtorja o tem, kako nam dosedanje védenje in znanje o proučevani problematiki oziroma osnovnih etičnih pojmih pri premostitvi vrednotne krize, $v$ kateri smo, lahko koristita, kot tudi za posamična vprašanja, o čem (naj) posamezniki kot tvorci sodobne družbe razmišljamo, kako (naj) se vedemo, odzivamo in kako (naj) ravnamo, kakšen odnos (naj) imamo do soljudi, za kakšne cilje oziroma običaje, metode, pravila in načela (naj) si prizadevamo ter kam nas takšno zasledovanje ciljev pravzaprav vodi - k dobremu ali zlu. 


\section{TEORETIČNA IZHODIŠČA PROUČEVANE TEMATIKE}

Da je osnovni pogoj za uspešno, zdravo, uravnoteženo in kakovostno življenje vsake sodobne družbe ravno v njenem vsakodnevnem iskanju moralnega odločanja in prizadevanju po krepitvi moralne drže njenih posameznikov, etični presoji in izgradnji etične infrastrukture, doslednem upoštevanju pravnih predpisov in pravil ter krepitvi vrednot, vrlin oziroma kreposti, je že prastaro dejstvo, pa vendar - če se danes ozremo okrog sebe in poskusimo zgolj laično oceniti stanje duha naše družbe, se zdi, kot da gre pri tem za povsem nov pojav, v katerem se nekateri posamezniki preprosto ne znajdejo več. Vedno bolj se nam zdi, da sodobna družba skoraj ne deluje več po nikakršnih drugih predpisih, kot le še po pravnih. Pa še to na način, da se predpisi kršijo ali pa se izrabljajo pravne praznine. Bojan Žalec meni, da ni temeljno etično vprašanje, kateri predpisi so pravilni, temveč kakšne posameznike naj bi z njimi oblikovali, kakšne vrline naj bi razvili v osebah, v otrocih. Predpisi so po njegovem potrebni, vendar so prazni in nezadostni brez vrlin. Golo uveljavljanje teh predpisov se zlahka zlorabi, če jih ne sprejmejo krepostni ljudje (Žalec, 2006, str. 166-167). Zato se tu zdi vprašanje »Ali nam res ne more priti do pameti dejstvo, da še ni bilo dobe, $v$ kateri bi se bolj deklarativno poudarjala enakost, obenem pa še nikoli ni bilo večjih razlik med ljudmi?« (Žalec, 2009, str. 346) povsem umestno. Če se navežemo na judovsko tragedijo, v kateri je bilo na Hitlerjev ukaz pobitih dvajset milijonov ljudi, od tega šest milijonov Judov, ugotovimo, da holokavst ni bil samo judovski problem, kakor tudi ne samo dogodek v judovski zgodovini, saj se je zgodil v moderni racionalni družbi, na visoki stopnji naše civilizacije in na vrhuncu kulturnega razvoja, zato je to problem sedanje sodobne družbe, civilizacije in kulture (Bauman, 2006, str. 15). Odsotnost etike oziroma njena entropija se namreč tudi danes vsak dan znova pojavlja v obliki različnih neetičnih vzgibov, vedenj in ravnanj, ki jih srečamo pri posameznikih na vsakem koraku. Po Grmičevem mnenju govoriti o svetovni etiki ni nobena utopija, temveč je tisto, kar je mogoče postaviti nasproti pojavom vsakovrstnega antihumanizma, nasilja, posebno še terorizma (Grmič, 2003, str. 77-82). Po mnenju Švajgerja sta dejavnika, ki vodita v razpad vsečloveških etičnih vrednot in vnašata $\mathrm{v}$ medčloveške odnose negativne vrednote, kot so pohlep, sovražnost, maščevanje in egoizem, ravno duhovna nebogljenost in pomanjkanje primarnega čuta o dobrem (Švajger, 2005, str. 115-116). Tudi rimski zakon pravi: »Quid leges sine moribus - Kaj koristijo zakoni brez navad« (Küng, 2008, str. 68-71). Po Brownu pa se najbolj kontroverzna nasprotja kažejo ravno med etičnimi in pravnimi vrednotami (Brown, 2003, str. 186).

Dejavnik, ki povzroča tako stanje, je poleg nizke stopnje kritične zavesti ljudi, da je etika pravzaprav edini predpogoj za rešitev iz krize, tudi nedemokratično oziroma nepolno delovanje pravne države, ki je v naši širši družbi zastavljeno tako, da nekaterih delov (etičnih) predpisov, na primer etičnega kodeksa javnih uslužbencev, sploh ni mogoče izvajati, saj so v resnici le prepisani po modelu Evropske unije in v nekaterih primerih sploh ne omogočajo vseh možnosti za učinkovito uveljavitev 
oziroma izvajanje v praksi. ${ }^{1}$ Podobno velja za pravne predpise. Strokovnjaki, ki proučujejo kriminal in sistemsko korupcijo v Sloveniji in drugod v svetu, namreč opozarjajo na dejstvo, da tudi sprejemanje (ne zgolj izvajanje) zakonov in drugih pravnih predpisov že lep čas ne poteka več skladno z vsemi postulati pravne in demokratične države, v kateri se namreč ve oziroma je točno določeno, kdo jih pripravlja in kdo jih sprejema oziroma kako (in tudi izvaja). V njih je veliko pravnih praznin ${ }^{2}$, na podlagi katerih se lahko tisti, ki jih pripravljajo in jih tudi spretno izkoriščajo, ob ravno tako spretnem svetovanju nekaterih pravnih strokovnjakov izmuznejo še tako majhni možnosti, da bi bili krivi oziroma obsojeni za kakršen koli nezakonit posel. Pri tem kmalu pridemo do odgovora na vprašanje, zakaj je okrog nas toliko neetičnih, pa vendar ne nezakonitih poslov in dejanj ${ }^{3}$.

Danes vrednote, vrline in kreposti, kot so dobrota, človeškost, prijaznost, moralnost, poštenost, prizadevnost, neoporečnost, skladnost, nepristranskost, enakost ipd. pravzaprav kar same kličejo po priznavanju vrednotnega sistema, ki je nujni pogoj za obstoj in delovanje posameznikov in organizacije oziroma celotne sodobne družbe. Javna uprava in vojska iz tega nista izvzeti - ravno nasprotno. V javni upravi in vojski imajo vrednote pomembno vlogo, gre tudi za javni interes, ki je v ospredju in je pred zasebnim. Tu naj bi bila ločnica med javnim in zasebnim jasno začrtana, državljani pričakujemo, da bodo procesi javnega upravljanja ob upoštevanju pravnih predpisov in pravnih pravil potekali ob najvišji stopnji moralnega odločanja, etičnega presojanja ter upoštevanja vrednotne podstati. Na podlagi navedenega je za njuno delovanje pomembno, da zaposleni (resnično) opravljajo svoje naloge na podlagi ustave, zakonov, izvršilnih in splošnih pravnih predpisov, predpisanih vojaških, etičnih in drugih pravil, zaradi česar (naj) ne bi prihajalo do nelegitimnih, nezakonitih ali protipravnih dejanj, zlorab pravnih predpisov in drugih podobnih kršitev na delovnem mestu. Haček meni, da so javni uslužbenci zavezani, da delujejo v javno dobro (Kos: Haček, 2001, str, 109). Empirično proučevanje leta 2000 je v 29 državah OECD pokazalo, da so najpomembnejše vrednote (po prednostnem vrstnem redu) v javni upravi nepristranskost, zakonitost, integriteta, preglednost, učinkovitost, enakost, odgovornost in pravičnost. ${ }^{4}$ John W. Brinsfield kot najpomembnejše ameriške vojaške vrednote izpostavlja lojalnost, zaupanje, predanost, sposobnost soočenja s skrajnostmi oziroma nevarnostmi, vdanost, zanesljivost, duhovno vzdržljivost in osebni pogum. Splošno o vrednotah in etiki v vojski pa pravi, da so te in

\footnotetext{
Glej Haček in Bačlija, Sodobni uslužbenski sistemi. Fakulteta za družbene vede, Ljubljana, 2007. Raziskava Noč.

2 Predmet pravnih praznin so tista družbena razmerja, ki niso zajeta s splošnimi in abstraktnimi pravnimi pravili, a so tako pomembna, da morajo biti pravno urejena. Ugotovitev, da gre za pravno praznino, je toliko bolj prepričljiva, kolikor ji uspe utemeljiti, da gre med drugim za nepopolnost formalnega pravnega zapisa, ki ni načrtno neurejena zato, ker bi se nanašala na dejavnost, ki je predmet človekovega svobodnega ravnanja (...) itn. Glej Pavčnik, Teorija prava. GV založba, Ljubljana, 2007. Poglavje VII-Pravne praznine.

Glej http://tvslo.si/predvajaj/intervju-s-strokovnjakom-za-sistemsko-korupcijo-bojanom-dobovškomava2.113421816/.

4 Glej Brezovšek in Haček v Upravna kultura, FDV, 2004.
} 
njihova usklajenost ter ustreznost vsebovane že v pojmu 'duty' oziroma dolžnost ${ }^{5}$. Paul Robinson kot najpomembnejše ameriške vojaške vrednote izpostavlja lojalnost, dolžnost, spoštovanje, nesebičnost (nesebično služenje), čast, integriteto in osebni pogum, kot najpomembnejše britanske vrednote pa nesebičnost (nesebična zavezanost), pogum, disciplino, integriteto, lojalnost in spoštovanje drugih, med najvišje rangirane kanadske vojaške vrednote pa prišteva dolžnost, lojalnost, integriteto in pogum. Skladno s slovensko Vojaško doktrino ${ }^{6}$ so domoljubje, čast, predanost, pogum, lojalnost in tovarištvo tiste vrednote, ki so opredeljene kot gonilna sila za uresničevanje poslanstva Slovenske vojske, večinoma so tudi v celoti upoštevane v Kodeksu vojaške etike Slovenske vojske. Tudi Edvard Kotnik je v svoji diplomski nalogi ugotavljal, katere vojaške vrednote so pri pripadnikih Slovenske vojske najvišje rangirane oziroma najbolj cenjene. Pokazalo se je, da so to (po prednostnem vrstnem redu) poštenost, pripadnost, tovarištvo, čast in pogum. Za čast se je izkazalo, da je med 71 anketiranimi pripadniki na lestvici vrednot zasedla šele četrto mesto (15,5 odstotka) in ne prvega, kot je avtor predvideval oziroma zastavil eno izmed svojih hipotez. Za poštenost kot najbolj cenjeno vrednoto pa se je izreklo 23,9 odstotka anketirancev ${ }^{7}$. Pri tem velja omeniti, da gre pri navedenem za raziskavo, opravljeno pred sprejetjem vojaškega kodeksa ${ }^{8}$. V kodeksu gre za vrednote, kot so pogum, spoštovanje, predanost, zanesljivost, dostojanstvo, zaupanje, vztrajnost, odgovornost, odločnost, lojalnost, tovarištvo, zvestoba domovini, poštenost in čast (Kodeks vojaške etike Slovenske vojske, 2009). Tudi Okovič je istega leta v svojem magistrskem delu prišel do podobnih ugotovitev. Prednostna lestvica vojaških vrednot pripadnikov Slovenske vojske, do katere je prišel med raziskovanjem, je sestavljena iz poštenja, pripadnosti, tovarištva, časti, poguma, delavnosti, zvestobe, spoštljivosti, iskrenosti, motiviranosti, urejenosti, nepristranskosti in usposobljenosti. Za poštenje kot najvišjo vojaško vrednoto se je tudi v njegovi raziskavi opredelilo največ pripadnikov (34,6 odstotka oziroma 18 od 52). ${ }^{9}$ Podobno je ugotovila tudi dr. Jakič Brezočnik, ki je v svoji raziskavi o rangiranju vojaških vrednot prišla do podobnega sklepa kot omenjena predhodnika. Na vzorcu 730 pripadnikov Slovenske vojske (tj. približno 10 odstotkov vseh) se je za poštenost (ne glede na status pripadnikov) kot najvišjo vojaško vrednoto izreklo največ anketiranih. Sledijo tovarištvo,

\footnotetext{
Glej John W. Brinsfield v Army Values and Ethics: A Search for Consistency and Relevance pravi, da je misija vojske nacionalna zmaga, misija etične vojske pa doseganje ciljev ob upoštevanju vrednot in kreposti, ki se zaključi s častjo.

${ }^{6}$ Vojaška doktrina je najvišji vojaškostrokovni dokument in podlaga za organiziranje in delovanje Slovenske vojske. Je tudi temeljni dokument, iz katerega izhajajo področne doktrine, navodila, učno-izobraževalna literatura in drugi vojaškostrokovni dokumenti.

Glej diplomsko delo Edvard Kotnik, Vojaška etika in etika v Slovenski vojski. 2008.

\& Pojem kodeks vojaške etike je vsebovan že v Zakonu o službi v Slovensko vojski (ZSSloV), ki v 5. členu določa, da ima Slovenska vojska svoj kodeks vojaške etike, ki ga sprejme Vlada Republike Slovenije in ga morajo pripadniki pri opravljanju svoje službe spoštovati.

Glej Okovič Dejan, Magistrsko delo, FDŠ, 2007, stran 106-107.
} 
spoštovanje, čast in ponižnost. ${ }^{10} \mathrm{Na}$ podlagi navedenega je mogoče povzeti in skleniti, da je pripadnikom Slovenske vojske poštenost ne samo najvišje rangirana vojaška vrednota, temveč tudi tista univerzalna vrednota, ki jo pričakujejo od vseh svojih sodelavcev, neodvisno od njihovega vojaškega statusa. Vendar tukaj previdno in predvsem roko na srce - ali jo pripadniki Slovenske vojske zgolj pričakujemo (od drugih) ali jo vendarle tudi (sami) uresničujemo.

Kot odziv na zahteve po čimprejšnjem in čim učinkovitejšem izboljšanju etičnega ravnanja ter izgradnji etične infrastrukture v družbi se tako pojavljajo različni načini in poskusi razprave o tem, kaj je moralno, etično, pravno in prav ter katere so tiste vrednote, na katere smo v nekaj desetletjih že skoraj v celoti pozabili. Pa vendar so te vrednote antipod moralno zavržnim in neetičnim ravnanjem, nepravilnostim, korupciji, kriminalu, kaznivim dejanjem ter celi vrsti kršitev, ki so skladno s pravno opredelitvijo označena kot slaba oziroma obsojanja vredna dejanja in za katera so skladno s pravnimi predpisi določene sankcije.

V času, v katerem živimo, gre vsekakor za nujnost osmislitve morale, etike in vrednotne podstati, saj smo po Cerarjevem mnenju tako kot drugi narodi tudi Slovenci padli na etičnem izpitu ${ }^{11}$. Gre namreč oziroma naj bi šlo za (ponovno) vzpostavitev tistega ${ }^{12}$, kar v današnji družbi že precej časa manjka, a je temeljno in nujno za nadaljnji obstoj. Gre za tako imenovani poskus rešitve oziroma ugotovitve vseh možnosti za izboljšanje stanja družbe, v kateri živimo in katere nesporni del smo. Slovenska vojska v tem poskusu ni izjema.

\section{METODOLOGIJA}

\subsection{Metode raziskovanja}

Pri proučevanju obravnavane tematike je bila največ uporabljena metoda zbiranja sekundarnih in terciarnih virov iz Slovenije in od drugod, nekoliko manj pa metoda zbiranja primarnih virov. Gre za vire priznanih slovenskih in tujih strokovnjakov oziroma znanstvenikov, ki proučujejo področja, navedena v prispevku. S to metodo so bila ugotovljena dejstva oziroma podani odgovori na zastavljena vprašanja, zlasti na splošno vprašanje, ki se nanaša na rešitev današnje družbe oziroma njen izhod iz krize. $Z$ analitičnim pristopom so obdelani teoretični pojmi, pojavi in procesi, povezani s področji morale, prava, etike in vrednot posameznikov $\mathrm{v}$ družbi. Raziskovalne metode, ki so uporabljene, so splošno teoretične, tj. miselne in logične, na primer deskriptivna, zgodovinska in komparativna ter analiza in sinteza. Deskriptivna metoda je namenjena opisu vseh pojmov, dejstev in postopkov, ki so

\footnotetext{
${ }^{10}$ Glej zbornik Javna etika in integriteta: odgovornost za skupne vrednote. Ljubljana, 2012. Dr. Manica Jakič Brezočnik, stran 296. Kot drugo najvišje rangirano vrednoto so civilne osebe uvrstile tovarištvo, vojaški uslužbenci in vojaki pa vrednoto spoštovanje, medtem ko so podčastniki v drugo najpomembnejšo vrednoto $v$ vojaški organizaciji združili spoštovanje, tovarištvo in čast, častniki pa so se odločili za tovarištvo in spoštovanje. Vrednota ponižnost pa je pri vseh omenjenih statusih zasedla zadnje mesto na lestvici vojaških vrednot.

${ }^{\prime \prime}$ Glej www.youtube.com/com/watch?v=bTR30CODmsy.

${ }_{12}$ Glej Svetovni etos Hansa Künga.
} 
kakor koli povezani z navedenimi pojmi oziroma se nanašajo nanje, ter njihova pravila in vrednotni sistem, pri čemer se prav tako nanašajo na mišljenje, razumevanje, dojemanje, vrednotenje in presojanje v prispevku navedenega. Z zgodovinsko metodo so predstavljena in ponazorjena nekatera dejstva o proučevanju etičnega vedenja in ravnanja posameznikov v družbi, začenši z opredelitvijo nastanka obravnavanih pojmov ter pregledom njihovih pravil skozi različna obdobja. S komparativno metodo so primerjana družbena, moralna, pravna in etična pravila. Z analizo in sintezo je bilo ugotovljeno, $\mathrm{v}$ čem se ta pravila med seboj razlikujejo in kaj imajo skupnega, tudi v povezavi z vrednotnim sistemom. Z uporabo domače in tuje strokovne ter znanstvene literature so opredeljeni pojmi, dejstva in postopki, ki so kakor koli povezani z moralnim, etičnim oziroma prav(n)(im) in vrednotnim delovanjem ter ravnanjem posameznikov v družbi, torej z vsem tistim, kar sestavlja in predstavlja etično infrastrukturo in vrednotno podstat vsake družbe.

\section{DRUŽBA IN DRUŽBENA PRAVILA}

\subsection{Družba}

Človek je družbeno bitje ali, kot je izpostavil Aristotel, 'zoon politikon' (družbena žival). Za človeka je značilno, da si zavestno postavlja cilje in si potem smotrno prizadeva, da bi jih uresničil, kar izhaja iz abstraktne narave njegove zavesti. Posameznik lahko obstaja le v povezavi z drugimi ljudmi. Zato tudi družbo opredeljujemo kot celoto medčloveških odnosov, pri čemer torej ne gre za aritmetično vsoto posameznikov, temveč za novo kakovost v objektivni stvarnosti, sestavljeni iz narave, družbe in človeka (Igličar, 2006, str. 9). Družba je zapleten in celovit pojav. Treba se je samo spomniti, kako silno množico najrazličnejših naravnih in umetnih ljudskih skupin obsega. Koliko je družin, rodov, plemen in narodov, koliko sosesk in občin, koliko dežel in držav, koliko verstev in cerkva, koliko različnih stanov, kakšna nepregledna množica najraznovrstnejših kulturnih in prosvetnih, verskih, humanitarnih, gospodarskih, strokovnih, stanovskih, političnih ter še nešteto drugih društev in organizacij. In koliko najrazličnejših naravnih in umetnih zunanjih in notranjih vezi se med vsemi temi tvorbami ter oblikami ljudskega sožitja vse vprek prepleta, jih po eni strani med seboj druži, po drugi pa ločuje (Gosar, 1994, str. 60).

\subsection{Družbena pravila}

V procesih družbene diferenciacije so se iz sprva enotnih družbenih pravil izločila pravna pravila kot norme za eksistenčno bistvene družbene odnose. Del družbenih norm je zgolj pravne oziroma pravno-tehnične narave (npr. oblika odločbe), del jih ima zgolj moralno naravo (zaupanje prijatelju), tretji del pa pomeni prekrivanje moralnih in pravnih norm. Pri tem so pogosti primeri, da je ohlapnejša moralna norma prelita $\mathrm{v}$ pravno, le da je bolj odrejena in natančna (lex certa). Tako je na primer norma, po kateri je korupcija slabo, nepošteno in zavržno ravnanje, v pravu opredeljena z določbami zakona o preprečevanju korupcije, kazenskega zakonika 
in še nekaterih drugih zakonov (Igličar, 2006, str. 9-11). Zakon o preprečevanju korupcije (ZPKor) je leta 2010 sicer nadomestil Zakon o integriteti in preprečevanju korupcije $\left(Z \operatorname{IntPK}{ }^{13}\right)$, pa vendar - bistvo ostaja enako v vsej svoji značilnosti.

\section{PRAVO IN PRAVNA PRAVILA}

\subsection{Pravo}

»Pravo je sistem kot celota učinkovitih pravnih pravil in pravnih načel, ki jih sankcionira država in s katerimi se v življenjsko pomembnih družbenih razmerjih urejata zunanje vedenje in ravnanje ljudi na vsebinsko pravilen način.« (Pavčnik, 2007, str. 27)

\subsection{Pravna pravila}

Pravna pravila ali pravne norme (lat. norma, slov. mera, pravilo) so temeljna normativna sestavina prava. Pravna pravila povedo, kako naj pravni subjekti ravnajo in se vedejo $\mathrm{v}$ družbenih razmerjih. Ravnanje in vedenje je pravna posledica, ki naj bo uresničena tedaj, ko se pravni subjekt znajde v določenih življenjskih okoliščinah. Prvotna (primarna) pravna posledica je dovolitev, zapoved ali prepoved vedenja in ravnanja, ki naj sledi ustreznim okoliščinam, v katerih se pravni subjekt že nahaja ali pa do njih utegne priti. Sankcija je tako šele drugotna (sekundarna) pravna posledica, ki naj doseže, da bo pravno pravilo vsaj drugotno učinkovalo. V naravi prava in pravnega pravila je, da je neka stopnja prisilnosti (sankcija kot prisilni ukrep) nerazdružno povezana s pravom. To misel nazorno zapisuje že Digeste: »Vrlina zakona je, da zapoveduje, prepoveduje, dovoljuje in kaznuje« (Les virtus haec est: imperare, vetare, permittere, punire - Modestinus, D., 1, 3, 7). (Pavčnik, 2007, str. 91) Za normalen potek družbenega življenja je danes potreben kar obsežen kompleks splošnih in konkretnih pravnih norm, ki ob moralnih, strokovnih in običajnih normah uravnavajo in usmerjajo človekovo družbeno delovanje (Igličar, 2006, str. 12). Upoštevanje prava in pravnih pravil še ne pomeni, da država s svojim državnim (javnim) aparatom na posameznike in s tem na družbo kot celoto deluje povsem zadostno. Tako bi morali uporaba prava oziroma pravne znanosti z vsemi pravnimi pravili in predpisi, pa tudi delovanje in ravnanje javne uprave in uporaba oziroma upoštevanje etike, hoditi z roko v roki. Žal pa danes praksa v svetu in doma kaže, da je tako čedalje manj.

\section{MORALA IN MORALNA PRAVILA}

\subsection{Morala}

Morala (iz lat. mos - običaj, nrav, moralis nraven, moralen) je skupek predpisov, norm, vrednot, idealov, ki so sankcionirani s posebno notranjo, subjektivno sankcijo, ki jo subjekt, oseba, posameznik 'uporablja' na sebi zaradi morebitnega kršenja omenjenih nravstvenih postavk. Morala je po Srukovem mnenju toliko bolj

\footnotetext{
${ }^{13}$ Zakon o integriteti in preprečevanju korupcije (ZIntPK), Uradni list RS, št. 45/10 z dne 4. 6. $2010 \mathrm{~s}$ spremembami in dopolnitvami.
} 
učinkovita, kolikor bolj je ponotranjena oziroma kolikor bolj jo oseba (p)osvoji. Vsebino nravstvenih predpisov, vrednot in norm bi zelo okvirno lahko opredelili tako: svetujejo, zahtevajo ali ukazujejo, kar je dobro, odsvetujejo, grajajo ali prepovedujejo, kar je zlo. Toda to dobro in zlo variirata od družbe do družbe, od enega socialnega okolja do drugega, od kulture do kulture, od ene nazorske grupacije do druge. Morala se po eni strani kar naprej spreminja, po drugi pa vrednote in norme obstajajo v njej kot stalnice, ki jo notranje povezujejo in dolgoročno osmišljajo (npr. dekalog ali deset božjih zapovedi, zlato pravilo »ne stori drugim, česar ne želiš, da bi drugi storili tebi« ipd.) (Sruk, 1999, str. 303-304).

V literaturi najdemo številne opredelitve morale in njene vloge, odvisne predvsem od stališč različnih strokovnjakov. »Moralo lahko opredelimo kot določeno in konkretno vsoto pravil in norm človekovega ravnanja, ki veljajo za brezpogojno obvezna in občeveljavna.« (Stres, 1999, str. 10) Po Hribarju je merilo uravnotežene morale »ravnotežje med ljubeznijo do samega sebe in ljubeznijo do drugega. Gre za merilo, ki ga poznamo iz krščanske zapovedi: Ljubi bližnjega kakor samega sebe. Ne bolj ne manj.« (Hribar, 1996, str. 35) Moralno delovanje ni neka dejavnost zunaj drugih dejavnosti, temveč nekaj več na vsakem področju, zato je jasno, da je poleg posebnega znanja potrebno še posebno vrednotno oziroma moralno znanje. Vsako ustvarjanje, vsako delovanje je namreč lahko vrednotno, če se zavedamo njegove vrednotne dimenzije in jo namerno uresničujemo (Šter, 1994, str. 166). Izraza morala in etika imata po svojem izvoru deloma enak pomen. P. Ricoeur kot eden najpomembnejših filozofov navaja, da po svojem izvoru izraza etika in morala ne zahtevata nobenega posebnega razlikovanja. Oba po njegovem označujeta pogled na življenje, ki vsebuje dve prvini: 1) zavest o tistem, kar je za človeka dobro in 2) zavest o dolžnostih, ki jih mora človek izpolniti. Izraz morala tako ostaja v veljavi za nekatera življenjska pravila, zapovedi in norme, posebno še, če so vezani na določen nazor ali izročilo (Stres, 1999, str. 11-12).

\subsection{Moralna pravila}

Moralna pravila ter standarde oziroma merila vrednotenja lahko razumemo kot moralna načela. Moralna načela kot standardi določajo moralni status dejanj, oseb, situacij, motivov, stanj, stvari ipd., moralna pravila pa pogosto razumemo kot vodila pri našem odločanju ali delovanju (Strahovnik, 2009, str. 14). Če našo pozornost v moralni filozofiji usmerimo na vlogo moralnih načel in pravil, lahko glede na to razlikujemo med tremi vrstami stališč, na primer: 1) moralni monizem - obstaja eno samo splošno načelo, ki predstavlja merilo moralne pravilnosti in napačnosti naših dejanj in kateremu moramo pri našem moralnem presojanju in delovanju slediti; 2) moralni pluralizem - obstaja več med seboj neodvisnih in neizvedljivih moralnih načel, ki so pomembna za moralno pravilnost in napačnost naših dejanj; 3) moralni partikularizem - moralna načela in pravila nimajo prave vloge pri določanju moralne pravilnosti in napačnosti naših dejanj. Kaj so pomembni moralni razlogi, je namreč v celoti odvisno od narave situacije pred nami (Strahovnik, 2006, str. 39).

Življenje bi bilo neznosno breme, če bi se morali ob vsakem dejanju vedno in v vseh podrobnostih sproti in na novo odločati, ali naj ga naredimo ali ne in kako. Večino 
naših dejanj uravnavajo navade in splošno sprejeta pravila. Čim močnejša, jasnejša, obsežnejša in nespornejša so, tem manj se človeku zastavlja vprašanje, kaj mora narediti. Ljudje zahodne civilizacije zavestno iščejo nekaj novega in kritično preverjajo izročila starega. Vendar je usodna težava v tem, da družbena pravila odpovedo ali pa pridejo v notranje protislovje ravno ob najbolj odločilnih življenjskih vprašanjih. Tako vprašanja po tem, kaj je prav in kaj ni, kaj se sme in kaj ne, kaj je človek dolžan in česa ni dolžan narediti, ne dobijo samo osebne razsežnosti, temveč tudi občeveljavno in občestveno. Obča veljavnost je ena osrednjih značilnosti moralnega zakona. Kar je dobro, pošteno in prav, je prav za vse, sicer ni več morale (Stres, 1999, str. 6-7). Tako kot kazniva dejanja določajo, kaj je prav in kaj ne, tako tudi družbena in moralna pravila določajo, kaj je pravilno in kaj napačno, le da slednja ob neupoštevanju po svoji definiciji niso kazniva, saj so etična in moralna vprašanja neformalna (Jelenko, 2010, str. 43). V sodobni družbi pravna pravila izhajajo iz moralnih, saj je znana ugotovitev, da je pravo minimum morale. Zato v večini primerov ravnanje po pravnih normah zagotavlja tudi moralnost tega ravnanja. Moralna norma »delaj dobro, izogibaj se slabega« je na različne načine uresničevana v pravnih normah in tudi v sodobni zakonodaji, ki temelji na človekovih pravicah in temeljnih svoboščinah (Igličar, 2006, str. 10).

\section{ETIKA IN ETIČNA PRAVILA}

\subsection{Etika}

Etika je po Rotu teoretična disciplina o nravnosti, nujna za odgovorno človekovo ravnanje. Eden izmed najpomembnejših pojmov, povezanih s človekovim ravnanjem, je vest. Vest nas po Rotu usposablja za pravilno presojo različnih moralnih dejanj (Rot v: Haček in Bačlija, 2007, str. 85). Pavičević pravi, da je etika nauk o morali (Pavičević, 1974, str. 7). Za Akvinskega je etika analiza človekovega dejanja v vsej njegovi resničnosti (McCabe, 2008, str. 91), Juhant pa v enem izmed svojih del povzema Aristotela, ki je menil, da etika vključuje tudi um in voljo, ki naj bi delovala usklajeno ter dosegala dobro kot cilj etičnega prizadevanja. Človek naj bi se po Aristotelovem mnenju moral nujno odločati v raznolikosti sveta, a je spoznavanje in določanje tega 'kako' zelo kočljivo, saj sta obe človekovi zmožnosti, um in volja, krhki in potrebni neprestane spodbude in usposabljanja. Če se um zmoti, zmota otežuje primerno odločitev, če potem zataji še volja, do odločitve sploh ne pride. Zgodi se tudi, da um pravilno spozna, a volja spoznanju ne sledi. Pri odločanju imajo namreč pomembno vlogo tudi človekova čustva, ki sicer niso najvišji, so pa najmočnejši dejavnik. Zaradi njih nastajajo motnje v delovanju, zato prihaja do zgrešenih dejanj, ki imajo lahko usodne posledice za posameznika ali skupnost. Ne glede na te omejitve je etika kot spretnost temeljna človeška dejavnost, saj usmerja vse človekovo delovanje in ga tako omogoča kot umsko bitje. Človek ima po njegovem prirojene sposobnosti, ki jih mora nenehno gojiti in oblikovati (kultivirati), da bi se utrdile in 'delovale', kot je treba. Temu služi okvir, ki ga daje etika (Juhant, 2009, str. 17-18). Juhant pravi, da je etika temelj človekovega odnosa do sebe, sveta in njegovih zadnjih temeljev. Meni, da gre pri etiki za človekovo umnost, ki da usmerja 
k prav(iln)emu delovanju, ki človeku omogoči dostojno življenje, preživetje in mu pomaga doseči tudi končno odrešitev (Juhant, 2009, str. 11). V nadaljevanju svojega razmišljanja o etiki navaja, da je njen namen dosegati dobro, kar pomeni usmerjati, ohranjati oziroma razvijati človeka v njegovi polni človeškosti, pri čemer smo ljudje $\mathrm{v}$ tem prizadevanju vezani na dialog. To prizadevanje se po njegovem mnenju gradi na vzajemnosti in medsebojnem dogovoru, v dialogu (Juhant, 2009, str. 25-26). Janez Juhant v svojem delu Etika I, Na poti $k$ vzajemni človeškosti, pravi, da je etika vso zgodovino veljala za najpomembnejši 'izdelek' filozofije. Pravi, da so stoiki filozofijo delili na logiko, ki je vrtna ograja, na fiziko, ki je rastoče drevo, in na etiko, ki je sad. Drugi misleci pa so videli filozofijo kot jajce, pri katerem je logika lupina, fizika beljak in etika rumenjak. Skratka, odločilni sad kulture in posebej filozofije so po njegovem smernice, kako naj se človek ravna, kako naj usmerja svoje delovanje, da bo potekalo prav in dobro, pri čemer je bistven poudarek na medsebojnem dialogu, zaradi katerega bomo po njegovem sploh preživeli (Juhant, 2009, str. 13-15). Posebno pomembna je za Slovence, ker po razpadu nekdanjega sistema ustvarjamo 'nove' vrednote in iščemo temelje medsebojnega sožitja v postmodernem svetu (Juhant, 2009, str. 11-12). Za Badioua etika pomeni iskanje dobrega 'načina bivanja' oziroma modrost delovanja. Tako pojmovana etika je zanj del filozofije, namreč tisti del, ki uravnava praktično eksistenco glede na predstavo o dobrem. Modrec je po njegovem tisti, ki zna ločiti stvari, ki so od njega odvisne, od tistih, ki niso, in ki usmeri svojo voljo na prve, medtem ko druge ravnodušno prenaša (Badiou, 1996, str. 7). Za Stresa je etika splošno teoretično in racionalno utemeljevanje moralnosti kot take. Etika je po njegovem mnenju filozofska panoga, ki se ne ukvarja toliko s posamičnimi normami in življenjskimi navodili, temveč je filozofsko razmišljanje o moralnosti, o tem, kaj je človek, da je tako neogibno moralno bitje, in čemu naj bo zavezan pri svojih moralnih presojah in odločitvah (Stres, 1999, str. 12). Svetlič pa pri opredeljevanju sodobne etike izpostavi dve vprašanji, in sicer: kako delovati in kako biti. Prvo vprašanje zadeva človekov odnos do drugih, drugo odnos do sebe (Svetlič, 2003, str. 13). Po Bostiču pa »/.../ etika vključuje način ravnanja oziroma obnašanja človeka do sočloveka, ustvarja primerne medsebojne odnose $\mathrm{v}$ družbi ter ustvarja in plemeniti konvencije ravnanj v družbi.« (Bostič, 2002, str. 10)

Vojaška etika pa je kritično razmišljanje o pravih in dobrih dejanjih ter obnašanju vojakov v procesu vzpostavitve miru med državo, vojsko in mednarodno skupnostjo. Po Baumanovem mnenju temelji vojaška etika na odsevu načel celovitega človeškega pristopa $\mathrm{k}$ nenasilju in sposobnosti na način, po katerem se ob poskusih groženj in organiziranega nasilja uporabijo ustavno dovoljena sredstva za preprečitev ali odpravo nezakonitega nasilja (Bauman, D., 2007, str. 17).

\section{2 Etična pravila}

Med kodificirana etična pravila spadajo etični kodeksi, ki naj bi jih zaposleni pri svojem delu upoštevali. Po Sruku je etična norma pravilo, načelo oziroma merilo v domeni nravstveno relevantnega delovanja. Etične norme po njegovem omogočajo presojanje in vrednotenje vsega tistega, kar lahko opredelimo kot moralno ali nemoralno. V vsaki družbi se po eni strani povezujejo z manifestacijami in momenti 
konkretne družbene biti, še zlasti z interesi in potrebami posameznikov ter skupin, po drugi pa z ideali in vzori. Sociolog Emile Durkheim je dognal, da nravstveni ideali izhajajo iz narave družbe. V razrednih družbah so nekatere etične norme (tudi vrednote in ideali) bliže tem, druge spet drugim družbenim skupinam. Kakor koli že, etična norma je vodilo oziroma pravilo, ki uravnava človekovo nravstveno relevantno življenje in ravnanje (Sruk, 1999, str. 135).

V domeno etike oziroma etičnih pravil sodobna literatura umešča tudi pojme, kot so etične oziroma moralne dileme, moralni konflikt in moralni preostanek. »Etične dileme spremljajo človekova dejanja v zasebnem in poslovnem življenju. Pogosto smo v dvomih, ali smo ravnali prav ali narobe, dobro ali slabo, moralno ali nemoralno.« (Primožič, 2005, str. 16-17) Neredko se pri svojem moralnem presojanju znajdemo v situaciji, ko ni preprostega odgovora na vprašanje o tem, kaj storiti. Soočeni smo s težko moralno odločitvijo, ki jo lahko spremlja tudi čustveno breme narave ali posledic te odločitve. V takšnih primerih rečemo, da smo se znašli v moralnem konfliktu oziroma pred moralno dilemo. Moralni konflikt nastane, ko se srečamo s situacijami, v katerih se naše temeljne moralne intuicije pokažejo kot nezdružljive, v katerih se na primer razkrije nezadostnost nekega moralnega načela ali so enako pomembne dolžnosti ali vrline v medsebojnem nasprotju (Strahovnik, 2009, str. 180-181). Moralne dileme Strahovnik deli na: 1) spoznavne in prave moralne dileme, prve vznikajo iz pomanjkanja in nezadostnih informacij o predmetu sodbe, medtem ko gre pri pristnih moralnih dilemah za (v grobem izenačen) konflikt med moralnimi razlogi ali obvezami; 2) samonaložene dileme in dileme vsiljene od zunaj. Samonaložene so tiste dileme, ki nastanejo zaradi delovalčevih predhodnih napačnih ali nepremišljenih dejanj. Takšen je primer dileme, ko podam dve različni obljubi, za kateri vem, da ju ne bo mogoče hkrati izpolniti. Dileme, ki so delovalcu vsiljene neodvisno od njegovih izbir, dejanj oziroma od zunaj, so neodvisne od moralne pravilnosti ali nepravilnosti delovalčevega predhodnega ravnanja; 3) dileme, povezane z zapovedmi (obligacijske dileme) in prepovedmi (prohibicijske dileme). Dileme, povezane z zapovedmi vznikajo iz situacij, v katerih je prisotnih več enako pomembnih zapovedanih dejanj (Sartrov mladenič), medtem ko prohibicijske dileme nastajajo tam, kjer gre za enako močne prepovedi, ki izločijo oziroma prepovedo alternativna ravnanja; 4) dileme, vključujoče več različnih moralnih načel (nesimetrične dileme), in dileme znotraj enega samega načela (simetrične dileme). Nesimetrične vključujejo več raznolikih načel (Sartrov mladenič), simetrične pa so dileme znotraj enega samega načela in zadevajo enak tip dejanja (Sofijina izbira); 5) dileme, vezane na eno osebo, in dileme, vezane na več oseb. Poleg običajnih dilem, ki so vezane zgolj na enega delovalca, si lahko zamislimo tudi dileme, ki so vezane na več delovalcev; 6) tragične dileme. To so nerešljive moralne dileme, ki jih spremlja občutek, da bomo naredili narobe, kakor koli bomo ravnali. Zdi se, da V njih ne moremo sprejeti prave odločitve (Strahovnik, 2009, str. 185-186).

Zanimiv način ponazoritve etičnega nesporazuma oziroma etične dileme v družbi nam v svojem delu Praktična etika podaja Peter Singer, ki pravi, da veliko ljudi nasprotuje splavu, izkoriščanju živali ali gradnji jezov na divjih rekah, vendar 
za uveljavitev svojega prepričanja ne kršijo zakona. Pravi, da nedvomno drži, da nekateri člani bolj konvencionalnih organizacij, ki si prizadevajo za ohranitev divjine, osvoboditev živali ali prepoved splava, nezakonitih dejanj ne zagrešijo, ker ne želijo biti denarno kaznovani ali oditi v zapor. Vendar pa so tudi taki, ki bi bili pripravljeni sprejeti posledice nezakonitih dejanj, a se jih vzdržijo zgolj zato, ker spoštujejo zakon in ravnajo skladno z njegovo moralno avtoriteto. Kdo ima prav v tem etičnem nesoglasju? Je naša moralna obveza, da ravnamo skladno z zakonom, če ta ščiti in dovoljuje reči, ki se nam zdijo popolnoma zgrešene? Jasen odgovor na to vprašanje je podal ameriški radikalec iz 19. stoletja Henry Thoreau. V svojem eseju, naslovljenem Civil Disobedience, je zapisal: »Se mora državljan, čeprav le za hip ali v najmanjši meri, odreči svoji vesti in jo prepustiti zakonodajalcu? Zakaj ima potemtakem vsak od nas vest? Menim, da bi morali biti najprej ljudje in šele nato podaniki. Veliko bolj zaželeno je gojiti spoštovanje do pravičnosti kakor do zakona. Edina obveznost, ki jo smem vzeti nase je, da bom vselej počel, kar menim, da je prav.« Thoreau in Wolff sta torej spor med posameznikom in družbo rešila v prid posameznika. Storiti moramo torej tisto, kar nam narekuje naša vest oziroma za kar se avtonomno odločimo, da bi morali storiti, in ne, kar nam narekuje zakon. Vsakršno drugačno ravnanje bi po njegovem pomenilo zanikanje naše sposobnosti etičnega odločanja (Singer, 2008, str. 280-281).

Moralni preostanek pa je po Strahovnikovem mnenju tisto, kar ostane po odločitvi oziroma ravnanju v situaciji moralnega konflikta. O takšnem preostanku je prvi obširneje govoril Williams, čigar glavna misel je, da moralni konflikt ni rešljiv brez preostanka, na katerega kažejo občutja obžalovanja, ki se pojavijo tudi v primerih, ko smo ravnali prav (Strahovnik, 2009, str. 186-187).

\section{VREDNOTE, VRLINE IN PREGREHE}

\subsection{Vrednote družbe in posameznika}

Vrednote so zapleten, celovit, na različne načine utemeljevan in koncipiran znanstveni ali filozofski pojem. Vrednote so lahko različni cilji - bodisi idealni, zgolj nazorski, bodisi realni, stvarni. Prav tako so vrednote različna spoznavna, moralno-etična, umetnostno-estetska, politična, verska in druga načela, norme in drže. Vrednote so pozitivne (želeno) in negativne (nezaželeno). Na Slovenskem je izraz vrednota uveljavil France Veber. Številni pisci so izraz vrednost uporabljali na gospodarskem, izraz vrednota pa na idejnem in nravnem področju (Janžekovič v: Sruk, 1999, str. 530). Vrednota je tisto, za kar nam v našem praktičnem življenju vselej že gre, kar nam vselej že nekaj velja. Vrednota je 'cenjeno in ocenjevano' in obstaja vselej le v razmerju do nas samih. Človek si sam postavlja vrednote in je zato tudi sam odgovoren zanje. Od človekovega gledišča pa je odvisno, kaj je zanj vredno in kakšne vrednote bo izbral (Sruk, 1999, str. 531). Stres o vrednotah kot pogoju za naš obstoj pravi, da ni res, da je združena Evropa nastala predvsem ali celo samo zaradi gospodarskih interesov, čeprav se je začela $\mathrm{v}$ imenu sodelovanja med francoskim premogom in nemškim jeklom. Na začetku združevanja evropskih narodov sta bili 
po njegovem mnenju čisto jasno navzoči in še bolj odločilni moralna ideja in zahteva po miru, medsebojnem spoštovanju, sodelovanju in spravi. Torej se je Evropa začela združevati na podlagi skupnih vrednot in zato, da bi te vrednote ohranila in okrepila. Tudi vsaka sodobna država je država, ki ni nastala spontano in nezavedno, temveč je bila na začetku novega veka zavestno zamišljena in narejena kot demokratična, svobodoljubna in pravična ter se je v naslednjih stoletjih v tej smeri dopolnjevala (Stres, 2003, str. 174-175).

Zaradi pojava totalitarizmov, ki imajo globoke historične in duhovne korenine, so se začele porajati misli, da so vrednote na splošno nekaj, kar spada k zgodovinski podobi človeka, resnica te podobe pa se je dokončno razodela prav v totalitarnih vzorcih. Zato je bilo treba narediti korak stran od zgodovinsko kompromitiranega mišljenja, v okviru katerega so se generirale vrednote kot take (ne le določene vrednote) (Senegačnik, 1994, str. 127). Bojan Žalec v knjigi Doseganje dobrega povzema del razmišljanja Charlesa Taylorja in pravi, da je pogoj za delovanje modernih družb identifikacija njihovih članov z družbo, ki ji pripadajo, in občutek teh članov, da ji pripadajo. Člani se morajo nekako zavedati, da je moderna družba skupen podvig. Pravi, da nimamo druge možnosti, kot da smo odprti domoljubi in da se borimo proti neodprtim oblikam domoljubja, saj ni demokracije brez domoljubja (Žalec, 2006, str. 151). »Drugemu stori to, kar želiš, da bi drugi storil tebi, « ni samo krilatica ali suhoparen pregovor brez vsebine, pač pa ima veliko globlji pomen. Primarno življenjsko vodilo človeka je, da svoje življenje in življenja soljudi v svoji okolici privede v stanje, ki ne bo negativno vplivalo na njegovo ugodje, pač pa celo tako daleč, da ga pozitivna energija iz okolice polni čustveno in duševno. Človek, ki čuti in se zaveda, kaj so vrednote, ne bo nikoli ravnal nevestno in nepošteno, saj mu to preprečujeta vest in težnja po dobrem. Samo duhovno zrela, etično in moralno krepostna oseba je sposobna ob vseh pasteh in stranpoteh sodobnega življenja ostati v svojih dejanjih, razmišljanjih in razsojanju na pravi poti (Švajger, 2005, str. 115-116). Med tem, kar ljudje govorijo, in tem, kar delajo, pa je globok prepad. Najzgovornejši dokaz za to so številni primeri 'žvižgačev', menedžerjev v podjetjih, ki so skušali opozoriti javnost na neetično vedenje v lastni hiši, pa so jih odpustili (Primožič, 2005, str. 16-17).

\subsection{Vrline in pregrehe}

Grški pojem arete, krepost, vrlina pomeni vrednost, veljavnost, sposobnost, izvrstnost, posebnost v stalni usmerjenosti volje na moralno dobro (lat. virtus - vrlina). Izvorno pomeni možatost, moškost (lat. vir - mož, moški). Pozneje pomeni to karakter/značaj (gr. hexis) in navado posameznika v odnosu do drugih. Krepost so za Grke tudi izvirnost, odličnost in sposobnost na nekem področju ravnati najbolje. $\mathrm{V}$ grškem razumevanju pomeni arete tudi sposobnost, ki pripada stvari po njenem bistvu. Vrlina je temeljna kategorija antične grške in pozneje rimske etične misli. Vrlina je nekakšna pot do najvišjega dobrega, je merilo najvišjega dobrega ali pa je istovetna z njim. Vrhovna vrlina je hkrati najvišje dobro, ker se s tem postavi vprašanje namena, cilja, smeri ali smisla delovanja kot moralnega delovanja (Pevec Rozman, 2009, str. 49). Vrline so po McCabu težnje po sprejemanju odločitev, zaradi 
katerih postanemo sposobnejši sprejemati odločitve, cilj vrline pa je biti kreposten (McCabe, 2008, str. 42). V zgodovini etike zaznamo različne koncepte pojmovanja vrline, zato je nemogoče govoriti samo o enem konceptu. Različni misleci navajajo različne in pogosto nezdružljive vrline, prav tako obstajajo tudi različne teorije o vrlini. Koncepti oziroma pojmovanja vrline se ne razlikujejo le skozi zgodovino, temveč tudi med posameznimi kulturami. Odnos med vrlinami in družbenim redom se spreminja. Tako je pri Homerju za zgled človeške odličnosti postavljen bojevnik, pri Aristotelu pa to vlogo prevzame atenski 'gentleman'. Aristotel govori o vrlinah, ki so bistvenega pomena za človekovo življenje, govori o velikodušnosti oziroma plemenitosti in duhovni veličini (gr. megalopsychia, lat. magnitudo animi). Še vidnejši kontrast z Aristotelovim katalogom vrlin pa zasledimo v Svetem pismu, natančneje v Novi zavezi. Aristotel med vrlinami, ki jih našteva, ne omenja vrlin, kot so vera, upanje in ljubezen, ki so za Novo zavezo bistvenega pomena. Prav tako pa Nova zaveza ne govori o vrlini, kot je phronesis (preudarnost) ali praktična modrost, ki je bistvenega pomena za Aristotela (Pevec Rozman, 2009, str. 48). McCabe pravi, da je Aristotelu politika pomenila študij o tem, kako ohranjati polis - in prvi del te študije je etika. To je podlaga, na kateri Akvinski proučuje vrline. Pravi: »Ker je človek po svoji naravi politična žival, se moralne vrline, kolikor so mu naravne, imenujejo politične vrline, kajti od njih je odvisno, ali se bo v družbenem življenju dobro vedel.« Polis torej potrebuje krepostne ljudi in je hkrati sredstvo, ki ljudem omogoča, da postanejo čedalje bolj krepostni. Ne gre samo za to, da zahteva, da morajo ljudje delati stvari, ki jih zahteva pravičnost, na primer govoriti resnico in ne goljufati drugih (kajti ljudje lahko te stvari delajo zaradi strahu pred kaznovanjem ali zaradi kakšnega drugega razloga); nujno je, da se ljudje sami po sebi nagibajo k takšnemu delovanju, da so pripravljeni tako delovati, to pa zanje pomeni, da so pridobili vrlino pravičnosti. Ljudje, ki so pripravljeni tako delovati, ki ljubijo pravičnost, seveda zelo pogosto postanejo grožnja vladajočemu razredu pokvarjene družbe (McCabe, 2008, str. 50-51). Eden najvplivnejših sodobnih etikov Alasdair Macintyre pri zgodovinskem proučevanju vrlin ugotavlja, da obstajajo različni koncepti vrlin, ki so med seboj nezdružljivi. MacIntyre namreč meni, da so vrline tiste lastnosti, ki jih človek mora imeti, da je njegovo življenje lahko dobro. Po njegovem so kreposti ali vrline preudarnost, zmernost, pravičnost, pogum, dobrohotnost, plemenitost, prijaznost, vljudnost, strpnost, radodarnost in ljubezen, ki jo verujoči kristjani poleg upanja in vere uvrščajo med teološke kreposti. Kreposti so po njegovem sredstvo za doseganje dobrega življenja in hkrati njegov cilj (MacIntyre, 2006, str. 187-188). MacIntyre govori o treh različnih konceptih vrlin: 1) vrlina je odlika (kvaliteta, lastnost), ki posamezniku omogoča, da odigra svojo družbeno vlogo, torej da opravi dolžnost, ki jo ima kot pripadnik neke skupnosti (Homer); 2) vrlina je odlika (kvaliteta, lastnost), ki posamezniku omogoča doseči določen človeški telos, naj bo ta naravni (Aristotel) ali nadnaravni (Akvinski); 3) vrlina je odlika, ki posamezniku koristi pri doseganju uspeha tako na zemlji kot v nebesih (Franklin) (Pevec Rozman, 2009, str. 116-118).

Murdoch kot eno izmed redkih vrlin izpostavi ponižnost, za katero pravi, da je nemodna in pogosto težko opazna. Le redko srečamo koga, v katerem kar žari, pri katerem presenečeni opazimo, da je brez nestrpnih pohlepnih tipalk jaza. Ponižen človek lahko 
zaradi tega, ker vidi sebe kot nič, vidi druge stvari takšne, kakršne so (Murdoch, 2006, str. 119). Ljudje smo včasih vse preveč usmerjeni v pregrehe (drugih), namesto da bi gledali in videli tiste, ki premorejo tudi vrline, in se ravnali po njih (Foot, 1997, str. 177). Glede na razmere in stanje pri nas in v svetu bi lahko celo rekli, da žal velikokrat še kako drži, da smo ljudje pravzaprav usmerjeni v to, kaj drugi naredijo narobe, namesto da bi odpravljali svoje napake (pregrehe) in razvijali ter utrjevali kreposti pri sebi ali se ravnali po svojem vedenju. Hans Küng pravi, da je svetovni etos nujen za celotno človeštvo. Poziva nas in nam skuša dopovedati, da bi nam moralo postati jasno, da negativni gospodarski, socialni, politični in ekološki razvoj 20. stoletja kliče po svetovnem etosu kot vsaj ex negativo nujnem za preživetje človeštva. Brez morale, brez splošno zavezujočih etičnih norm, brez 'globalnega standarda' so narodi v nevarnosti, da zaradi kopičenja težav doživijo krizo, ki lahko privede do družbenega kolapsa, to pomeni do gospodarskega zloma, demontaže socialnega reda in politične katastrofe. Drugače povedano: potrebujemo osmislitev etosa, človekove osnovne nravne drže; potrebujemo etiko, filozofski in teološki nauk o vrednotah in normah, ki naj vodijo naše odločitve in dejanja. Krizo moramo razumeti kot priložnost, na katero moramo najti odgovor. Po njegovem bo prihodnost gradila etika odgovornosti. Vodilo za tretje tisočletje bi se moralo glasiti: odgovornost svetovne družbe za svojo lastno prihodnost, odgovornost za sodobnike in okolje, vendar tudi za prihodnje rodove (Küng, 2008, str. 59-66). Küng poudarja, da mora etika v postmoderni zaradi človekovega blagra in preživetja človeštva spet postati javna potreba najvišjega pomena. Tudi današnji ekonomisti bi se morali zavedati, da so veliki evropski gospodarski in družbeni teoretiki od Aristotela in Platona prek Tomaža Akvinskega do moralnega filozofa in utemeljitelja moderne ekonomije Adama Smitha gledali na gospodarstvo in politiko v etičnem kontekstu. Človeka ni mogoče poboljšati z vedno več zakoni in predpisi, seveda pa tudi ne zgolj s psihologijo in sociologijo. Tako v velikem kot malem smo vendar soočeni z isto stvarnostjo: strokovno znanje še ni smiselno znanje, predpisi še niso usmeritve in zakoni še niso navade. Tudi pravo potrebuje moralni temelj. Kaj pomagajo posameznim državam ali organizacijam, naj bodo to EU, ZDA ali OZN, vedno novi zakoni, če večina ljudi sploh ne misli na to, da bi jih izpolnjevala in vedno najde dovolj sredstev in poti, da neodgovorno uveljavi svoje ali kolektivne interese (Küng, 2008, str. 68-71).

\section{RAZPRAVA IN UGOTOVITVE}

Vsesplošna kriza izpred nekaj let je povzročila odsotnost morale in etike, zlorabo predpisov in razkroj vrednotnega sistema. Pri slednjem ni mišljeno, da so v težavah vrednote, kajti vrednote se ne razkrajajo. Razkroj nastaja zaradi odnosov, ljudi, družbe oziroma njenih posameznikov. Nastaja zaradi udarnih učinkov globalizacije, vplivov nenehnih tehnoloških sprememb, številnih inovacij, pretirane tekmovalnosti, prekomerne težnje po doseganju najvišjih ciljev in položajev v družbi, pretiranega pohlepa in hlastanja po materialnih dobrinah, brezglavega potrošništva in prekomernega zadolževanja, brezmejne zavezanosti in predanosti ekonomskim dobičkom ter (s)prejemanja osebnih oziroma zasebnih koristi, izjemno hitrega in pogosto nepremišljenega načina odločanja ter zaradi tega zelo stresnega načina življenja. Zaradi 
vsega tega prihaja do različnega razmišljanja, zaznavanja, sprejemanja, dojemanja oziroma vrednotenja, kaj je (sploh še) dobro, vredno, pošteno, moralno, etično, pravično, pravno in prav.

V prispevku je bilo ugotovljeno, da so si obravnavani etični pojmi v marsičem zelo podobni, da se med seboj prepletajo in dopolnjujejo. Kot odgovor na vprašanje, kaj je moralno, je bilo ugotovljeno, da je to tisto, kar velja za brezpogojno obvezno in občeveljavno za vse posameznike v družbi, pri čemer imajo pomembno vlogo moralna pravila, ki so naše vodilo pri odločanju, vedenju, ravnanju in delovanju. Kot odgovor na vprašanje, kaj je pravno, je bilo ugotovljeno, da gre za upoštevanje temeljnih pravnih pravil, ki določajo, kako naj se posamezniki v družbi vedemo in ravnamo, da nas ne doletijo pravne sankcije. Pri pravu gre tudi za minimum morale - pravna pravila namreč izhajajo iz moralnih. Pri etičnem vedenju, ravnanju in delovanju je bilo ugotovljeno, da gre za modrost delovanja, iskanje dobrega oziroma nauk o morali, pri čemer ima pomembno vlogo posameznikova vest. Za etiko in moralo je bilo ugotovljeno, da se med seboj prepletata, in sicer v zavedanju o tem, kaj je za posameznika dobro, ter v zavedanju o dolžnostih, ki jih posameznik mora izpolniti. Etično vedenje ni znanje o tistem, kar obstaja, kot obstajajo različne stvari - etika govori o tem, kaj naj bi bilo, kaj bi moralo biti, in ne o tem, kar v resnici je. Enaka ugotovitev velja tudi za pravo - ne koristijo nam hipertrofija pravnih predpisov ter številne konvencije o ravnanju v družbi, če pri posameznikih ni dozorela (za)vest, da bi jih tudi uresničevali/izpolnjevali (in tudi pripravljali tako, da pri tem ne bi mislili zgolj na svoje interese oziroma osebne koristi). V tem kontekstu imata poleg moralnega odločanja in prav(n) ega ravnanja vsakega posameznika pomembno vlogo tudi etičnost delovanja ter stopnja osebne integritete. Na (ne)moralno odločanje, (ne)etično vedenje in ravnanje, (ne)prav(n)o (mišljeno kot pravo in prav oziroma pravičnost ${ }^{14}$ ) delovanje posameznikov ter odstiranje vrednot iz našega vsakdana vplivajo številni dejavniki, kot so posameznikove osebnostne lastnosti, duhovna zrelost, etična in moralna krepost, prisotnost primarnega čuta o dobrem, izobraženost, sodelavci, prijatelji oziroma bližnji, okolje, v katerem živimo in delujemo, splošne družbene razmere in drugi podobni dejavniki. Zato je tudi odgovor na vprašanja, kako naj posamezniki kot tvorci družbe razmišljamo, kako naj se vedemo, odzivamo in kako naj ravnamo, kakšen odnos naj imamo do soljudi, za kakšne cilje, običaje, metode, pravila in načela naj si prizadevamo ter kam nas takšno vedenje in ravnanje pri tem vodita, vse prej kot preprost in enopomenski. Pri tem gre namreč (tudi) za izpolnitev (pred)pogojev oziroma uresničitev dejavnikov, kot so stopnja zavedanja oziroma stanje kritične zavesti posameznika o situaciji, v kateri je (smo), iskreno voljo (in željo) po izboljšanju stanja oziroma spremembo na boljše ter resnično angažiranost, pri čemer je pravzaprav mišljeno nenehno (vsakodnevno) prizadevanje po dobrem (kot najvišje dobro). Šele ko so izpolnjeni vsi ti dejavniki, lahko pričakujemo, da bomo lahko živeli dostojno, človeka vredno življenje, ki bo prežeto s temeljnimi univerzalnimi pravicami in vrednotami, moralnim odločanjem, etičnim vedenjem in ravnanjem ter dobrimi medsebojnimi odnosi, naša načela, vzgibi, nameni in cilji, po katerih bomo delovali, pa bodo zakoniti,

${ }^{14}$ Pravičnost je temeljna pravna vrednota, ki se osredinja na to, kako naj bodo dobrine in bremena razdeljeni in izravnani med pravnimi subjekti oziroma glej Pavčnik, poglavje 4.2 Pravičnost in pravo, str. 605. 
jasni, nedvoumni in pošteni, če ne, je kakršen koli poskus graditve oziroma ponovne vzpostavitve etične infrastrukture oziroma osmislitve svetovnega etosa v naši družbi obsojen na propad. Brez naše volje, prizadevnosti, pristnosti, iskrenosti, poštenja, delavnosti, truda, upoštevanja vrednotne podstati, moralnih vzgibov in etičnega vedenja namreč ni mogoče pričakovati nikakršnih sprememb. Za etične vrednote in neetično vedenje in ravnanje namreč velja, da so v medsebojni odvisnosti. Več ko ima posameznik vrednot, manj bosta njegovo vedenje in ravnanje neetična. Bolj ko je vedenje posameznikov etično, večja je možnost za dosego sprememb (v družbi) na boljše. Tudi pri korupciji je tako, saj je ta zelo odvisna od standarda etičnih vrednot v družbi. Brez močne moralne in etične utrdbe ne moremo pričakovati, da politiki, vodilni javni uslužbenci in tudi pripadniki Slovenske vojske ne bodo hitro podlegli negativnim dejavnikom (npr. dejavnikom tveganja za korupcijo, izdaji, nasprotju interesov ipd.), ko sprejemajo proračun, izvajajo javne natečaje, opravljajo zahtevne misije in operacije v imenu domovine oziroma zanjo ter opravljajo druge pomembne naloge, ki naj bi (nujno) upravičile njihovo javno upravljanje oziroma odločanje ter delovanje $\mathrm{v}$ javnem interesu. Predvsem od vojakov država in njeni državljani pričakujemo zgled, doseganje ciljev, ki temeljijo na pravni, vojaški, moralni, etični in vrednotni podstati, kamor spada vse, kar se pri posameznikih prepoznava kot dobro, pošteno, vestno, enakopravno, prijazno, zrelo, preudarno, nepodkupljivo, pregledno, nediskriminatorno, prizadevno, lojalno, moralno, pogumno, domoljubno, zakonito, strokovno in etično. Za doseganje naštetega pa so predvsem in najprej potrebni zadostna stopnja kritične zavesti posameznikov, hotenje po dobrem in spoznanje, da je vse to tudi potrebno.

Glede na to, da v naši družbi še vedno ni zaznati pomembnejših sprememb na bolje, za katere so odgovorni oblastniki (npr. zavest o odgovornosti in dolžnosti, povezanosti in solidarnosti ipd. ${ }^{15}$ ), je nedvomno nujno in smiselno čim prej začeti na individualni ravni vsakega posameznika, kajti čas v kontekstu zapisanega zagotovo ni naš zaveznik. Iz konteksta ni izvzeta niti Slovenska vojska, ali kot je dejal Michael Haubl: »Vojak v službi svoje države naj se obravnava kot povzročitelj varnosti in svobode naroda - vendar pod pogojem, da za utrditev narodovega miru svoje naloge izvaja pravično. $\ll^{16}$

Če torej navedeno strnemo v eno samo skupno in splošno ugotovitev, bi za prihodnje nikakor ne bilo pretirano in prehitro reči, da brez preobrazbe našega uma, duše, duha in srca oziroma novega razsvetljenstva pripadniki tega planeta ne bomo uspeli premagati vrednotne krize, v kateri smo. Od tu naprej pa vodi pot, ki se imenuje »od misli $\mathrm{k}$ besedam in od ondod $\mathrm{k}$ dejanjem $\ll$.

\footnotetext{
${ }^{15}$ V tem kontekstu mišljena »sodobna« slovenska družba ter v povezavi z njo naši poverjeniki in oblastniki ter znotraj tega pred nekaj dnevi izdano zaključno poročilo Komisije za preprečevanje korupcije o nadzoru nad premoženjem predsednikov parlamentarnih strank, številka 06259-1/2013/1 z dne 7. 1. 2013. Dostopno na https://www.kpk-rs.si/sl/nadzor-in-preiskave/odlocitve-in-mnenja-komisije/zakljucne-ugotovitve/01/2013/ zakljucno-porocilo-nadzora-nad-premozenjskim-stanjem-predsednikov-parlamentarnih-strank-ki-so-hkratifunkcionarji-in-zavezanci-na-tem-podrocju.

${ }^{16}$ Glej Ethica 2006, Enquete des Instituts für Religion und Frieden, str. 75. Dostopno na http://www.irf.ac.at.
} 
Sklep Za proučevane temeljne etične pojme iz prispevka je bilo ugotovljeno, da bodo morali čim prej (ponovno) postati javna potreba najvišjega pomena - kajti če želimo na sedanje izzive krize najti ustrezne odgovore, je nujno čim prej uveljaviti moralno in $\operatorname{prav(n)o~ravnanje~in~pristno~delovanje,~sprejeti~etiko~odgovornosti~družbe~za~boljšo~}$ skupno prihodnost ter okrepiti vrednotno podstat, bodisi v zasebni bodisi v javni sferi našega delovanja. Na nas je, da se tega lotimo konkretno, čim prej, čim bolj zavzeto in predvsem z najvišjo mogočo stopnjo integritete. Spremembe sicer ne bodo vidne oziroma se ne bodo zgodile čez noč, kajti morala, etika, integriteta in vrednote potrebujejo svoj čas, da jih družba ponotranji, bodo pa vsekakor prispevale k boljšemu jutri. Nihče pa nam ne more preprečiti, da tega projekta, ki se mu reče svetovni etos, sami pri sebi ne moremo začeti uresničevati že danes. In pri tem pripadniki Slovenske vojske niso nobena izjema, ne glede na starost, spol, staž, položaj ali čin.

1. Badiou, A., 1996. Etika. Razprava o zavesti in zlu. Društvo za teoretsko psihoanalizo, Ljubljana.

2. Bauman, D., 2007. Militärethik. Das Institüt für Theologie und Frieden. Hamburg.

3. Bauman, Z., 2006. Moderna in holokavst. Študentska založba, Ljubljana.

4. Bostič, A., 2002. Upravna kultura in etika upravnega dela javnih uslužbencev. Upravna akademija.

5. Brezovšek, M., in Haček, M., 2004. Upravna kultura. FDV.

6. Brinsfield W., John, 1998. Army Values and Ethics: A Search for Consistency and Relevance. Parameters. str. 69-84.

7. Brown, B., 2003. Ethic and Public Policymaking: An Incomplete transition in Central and Eastern Europe. V: Potuček, Martin, Leloup, Lance, Jenei, Gyorgy, Varadi, Laszlo (ur.). Public Policy in Central and Eastern Europe. The Network of Institutes and schools of Public Administration in Central and Eastern Europe, Bratislava.

8. Cerar, M., 2012. O etični občutljivosti in prizadevnosti v sodobnem svetu. Socialna akademija. Ljubljana, 16. 10. 2012. Dostopno na: www.youtube.com/com/ watch $?=b T R 30 C O D m s y$.

9. Dobovšek, B., 2011. Intervju s strokovnjakom za sistemsko korupcijo Bojanom Dobovškom. Ljubljana, MMC RTV SLO. 17. 9. 2011. Dostopno na: http://tvslo.si/ predvajaj/intervju-s-strokovnjakom-za-sistemsko-korupcijo-bojanom-dobovškomava2.113421816/.

10. Foot, Ph., 1997. Virtue and vices. V: Crisp, Roger in Slote, Michael (ur.). Virtue ethics, Oxford University Press, New York.

11. Gosar, A., 1994. Sodobna socialna etika. Založba Rokus, Ljubljana.

12. Grmič, V., 2003. Misli iz šole življenja. Založba Unigraf, Ljubljana.

13. Haček, M., 2001. Sistem javnih uslužbencev, Fakulteta za družbene vede, Ljubljana.

14. Haubl, M., 2006. Die Katolische Militärseelsorge im Bundesheer seit dem Jahr 1956. V: Freistetter W. (ur.). Ethica 2006. Institut für Religion und Frieden.

15. Igličar, A., 2006. Moralna in pravna pravila za človekovo družbeno delovanje. V: Vlaj, Stane (ur.). Etično upravljanje občin, Ljubljana, Inštitut za lokalno samoupravo pri Fakulteti za upravo, Ljubljana.

16. Jakič Brezočnik, M., 2012. Vrednote in zaznave uresničenosti terminalnih, individualnih in vojaških vrednot pripadnikov Slovenske vojske. V: Kečanović, Bećir. Javna etika in integriteta: odgovornost za skupne vrednote. Komisija za preprečevanje korupcije, Ljubljana. 
17. Jelenko, A., 2010. Spopad z moralo. Razmišljanja o pomenu moralnih vrednot. Exlibris, Grosuplje.

18. Juhant, J., 2009. Etika I. Na poti k vzajemni človeškosti. Študentska založba, Ljubljana.

19. Kodeks vojaške etike Slovenske vojske. Št. 00718-3/2009-5. Vlada Republike Slovenije. Ljubljana, 9. 7. 2009.

20. Kotnik, E., 2008. Vojaška etika in etika v Slovenski vojski. Visoka komercialna šola Celje.

21. Küng, H., 2008. Svetovni etos. Društvo 2000, Ljubljana.

22. MacIntyre, A., 2006. Odvisne racionalne živali: zakaj potrebujemo vrline. Študentska založba, Ljubljana.

23. McCabe, H., 2008. Dobro življenje. Etika in iskanje sreče. Zbirka Claritas; 51. Študentska založba, Ljubljana.

24. Murdoch, I., 2006. Suverenost dobrega. Zbirka Claritas; 45. Študentska založba, Ljubljana.

25. Okovič, D., 2007. Problem etičnih odnosov v Slovenski vojski. Fakulteta za državne in evropske študije. Kranj.

26. Pavčnik, M., 2007. Teorija prava. GV založba, Ljubljana.

27. Pavićević, V., 1974. Osnovi etike. Beogradski izdavačko-grafički zavod, Beograd,

28. Pevec Rozman, M., 2009. Etika in sodobna družba. MacIntyrejev poskus utemeljitve etike. Nova revija, Ljubljana.

29. Primožič, E., 2005. Živeti z etiko v javni upravi in Slovenski vojski. Bilten Slovenske vojske. September 2005, letnik 17, št. 2, str. 7-20.

30. Robinson, P., 2007. Ethics Training and Development in the Military. V: H. Taylor, Robert (ur.) Parameters. US Army War College, letnik XXXVII, št. 1.

31. Senegačnik, B., 1994. Vrednote med zgodovino in neminljivim. V: Videtič, Jernej, Senčar, Igor (ur.). Slovenija - vrednote in prihodnost, Ljubljana.

32. Singer, P., 2008. Praktična etika. Krtina, Ljubljana.

33. Sruk, V., 1999. Leksikon morale in etike. Ekonomsko-poslovna fakulteta, Maribor.

34. Strahovnik, V. 2006. Relativism, Contextualism and Partikularism in Ethics. V: Baccarini, Elvio (ur.). Relativism: proceedings of the internatonal conference. Muzej moderne $i$ suvremene umjetnosti, Rijeka.

35. Strahovnik, V., 2009. Moralne sodbe, intuicija in moralna načela. Inštitut za simbolno analizo in razvoj informacijskih tehnologij, Velenje.

36. Stres, A., 1999. Etika ali filozofija morale. Družina, Ljubljana.

37. Stres, A., 2003. Vrednote kot pogoj za naš obstoj. V: Uran, Rudi (ur.). Pogovori o prihodnosti Slovenije pri predsedniku republike o vrednotah, Ljubljana.

38. Svetlič, R., 2003. Dve vprašanji sodobne etike. Založba Goga, Novo mesto.

39. Šter, J., 1994. Kaj je moralno. DAVEAN, Ljubljana.

40. Švajger, F., 2005. Etika v javnem življenju in v državni upravi. Dignitas. 2005, št. 23/24 (december 2004/januar 2005), str. 98-116.

41. Furlan in drugi, 2006. Vojaška doktrina. Poveljstvo za doktrino, razvoj, izobraževanje in usposabljanje. Ljubljana.

42. Zakon o integriteti in preprečevanju korupcije (ZIntPK). Uradni list RS, št. 69/2011 z dne 2.9. 2011, s spremembami in dopolnitvami.

43. Zakon o službi v Slovenski vojski (ZSSloV). Uradni list RS, št. 68/2007 z dne 30. 7. 2007.

44. Žalec, B., 2006. Doseganje dobrega. Študentska založba, Ljubljana.

45. Žalec, B., 2009. Gorečnost naših dni: Na poti k svetovni kulturi in civiliziranosti. V: Žalec, Bojan (ur.). Srd in čas, Študentska založba, Claritas; 57, Ljubljana. 